\title{
The Caregiver Reported Autistic Symptoms in Preschool Children: Findings of Chandigarh Autism Screening Instrument (CASI) Linked Screening from North India
}

\author{
Jaison Joseph ${ }^{1}$ Komal Hooda ${ }^{1}$ Indu Chauhan ${ }^{1}$ Komal Dhull ${ }^{1}$ \\ ${ }^{1}$ College of Nursing, Pt. B. D. Sharma University of Health Sciences, \\ Address for correspondence Jaison Joseph, MSc, PhD, College of \\ Rohtak, India \\ Nursing, Pt. B. D. Sharma University of Health Sciences, Rohtak \\ 124001, India (e-mail: jaisonjsph@yahoo.com).
}

\begin{abstract}
Background Autism is a neurodevelopmental disorder and can be early detected with the aid of screening tools. Chandigarh autism screening instrument (CASI) is a newly developed tool to screen autistic symptoms among children aged between 1.5 to 10 years in the north Indian Hindi speaking population.

Objective In this study, we evaluated the caregiver report of autistic symptoms in preschool children (3-6 years) attending selected schools of Rohtak.

Materials and Methods The index study was conducted among 225 caregivers of school-going children aged between 3 to 6 years. Social and communication disorders checklist (SCDC-Hindi) and CASI was used to measure autistic symptoms. The modified Kuppuswamy scale was used for assessing the socioeconomic status of the caregivers. Results The autistic symptoms varied from 2.2 to $18.7 \%$, depending upon the CASI (cutoff score of 10) and SCDC (cutoff score of 9) measurements. The items in the

Keywords

- Chandigarh autism screening instrument (CASI)

- autistic symptoms

- screening

- preschool children shorter four-item version (CASI Bref) of CASI were found to be the predictors of autistic symptoms in this population. Children's gender, age, and socioeconomic status were not found to have any association with autistic symptoms in this setting.

Conclusion The study provides preliminary evidence in relation to the CASI-linked screening for autistic symptoms among preschool children. The shorter version of CASI (CASI Bref) can be an efficient quick screener for autistic traits, but the full version of CASI needs to be validated as per age-appropriate autism screening tools.
\end{abstract}

\section{Introduction}

Autism is a developmental disability that may occur during the early developmental stages of life. ${ }^{1}$ The diagnosis of autism is typically based on behavioral symptoms and can be detected early with the aid of screening tools. ${ }^{2}$ The recent evidence suggests prevalence of $0.09 \%$ for autism spectrum disorders (ASD) in India. ${ }^{3}$ There is a dearth of epidemiological studies on autism in India and most of the reported studies are derived from the clinic-based data. ${ }^{4}$ The symptoms of autism may manifest at an early age in children, and screening and related intervention result in better outcome of cognitive and behavioral problems. ${ }^{5}$ However, the wide range of behavior during the younger age level causes underrecognition and dilemma, leading to a delay in the identification of autism. ${ }^{6}$ Therefore, screening is of pivotal importance to understand the exact magnitude of the problem. Most of the screening tools pertaining to autism are of Western origin, and there is a lack of a culturally congruent scale in the Indian setting. ${ }^{7}$ The available evidence suggests the need for a valid, indigenously developed autism screening instrument for community surveys in India. ${ }^{8}$ The Hindi version of Chandigarh autism screening instrument (CASI) is a validated scale for screening autistic symptoms with adequate sensitivity and specificity in children aged between 1.5 to
DOI https://doi.org/ 10.1055/s-0040-1721167 ISSN 0976-3147. (c) 2021. Association for Helping Neurosurgical Sick People.

This is an open access article published by Thieme under the terms of the Creative Commons Attribution-NonDerivative-NonCommercial-License, permitting copying and reproduction so long as the original work is given appropriate credit. Contents may not be used for commercial purposes, or adapted, remixed, transformed or built upon. (https://creativecommons.org/licenses/by-nc-nd/4.0/) Thieme Medical and Scientific Publishers Pvt. Ltd., A-12, 2nd Floor, Sector 2, Noida-201301 UP, India 
10 years. ${ }^{9}$ The clinical features of autism may change as the child grows up, and there is a paucity of age-matched replication of research related to CASI-linked screening for ASD..$^{10}$ In this study, we used CASI to evaluate the caregiver report of autistic symptoms in preschool children (3-6 years) attending selected schools of Rohtak, Haryana.

\section{Materials and Methods}

This cross-sectional survey included the caregivers of preschool children attending seven schools of Rohtak district, Haryana, India. Caregivers were operationally defined as the caretaker or the parent who shares the great responsibility of the daily care of children. The study setting was conveniently selected, and the concerned teachers were requested to obtain the completed research questionnaires from the study subjects. The native vernacular language of the community is Hindi. Therefore, the Hindi version of the screening tool was used for data collection. The study included caregivers of eligible children who were able to provide consent, as per the information available on the participant information sheet, and who can read and write the Hindi language. The study was approved by the Institutional Ethical Committee (Reference No. IEC/18/583)

The Hindi versions of CASI, CASI-Bref, and SCDC were used for assessing the autistic symptoms. CASI is a 37-item questionnaire in Hindi, with adequate sensitivity and specificity, and a cutoff score of $\geq 10$, which is considered a risk for autism. CASI-Bref is a simple, shorter version of CASI, with the following four items: eye contact, the ability to communicate needs through verbal or nonverbal means, peer interaction, and odd, repetitive behavior. A score of more than two was considered at risk for autism. ${ }^{9}$ SCDC measures the social and communicative behavior of autism. The Hindi version of SCDC is identified as a valid tool and a cutoff score of 9 was used for measuring autistic symptoms in a previous schoolbased study conducted in the Indian setting. ${ }^{11}$ The modified Kuppuswamy scale was used for assessing the socioeconomic status of the caregivers.

We distributed a total of 400 research questionnaires, of which 225 caregivers completed and were available for analysis.

\section{Statistical Analysis}

Sociodemographics and clinical variables were expressed in frequency, and nonparametric test was done to find out the association between sociodemographic variables and scores of screening tools. Logistic regression analysis was done to predict the autistic symptoms, as per CASI-Bref items. Cohen's Kappa and correlation coefficient tests were calculated to study the concordance between the screening instruments. All the analyses were done using SPSS 15.0 version.

\section{Results}

A total of 225 preschool children were enrolled in the study with 130 (57.8\%) boys. A major proportion of the subjects belonged to the age group of 61 to 72 months ( $n=94 ; 41.8 \%$ ) and lower-middle socioeconomic status $(n=95 ; 42.3 \%)$ (-Table 1). The autistic symptoms were varied from 2.2 to $18.7 \%$, depending upon the CASI (cutoff score of 10 ) and SCDC (cutoff score of 9) measurements, respectively. The mean (SD) score of CASI was 4.62 (3.53) and SCDC was 4.99 (4.73). Autistic symptoms were more reported in boys (1.8-10.2\%) and associated with middle socioeconomic status (11.6$14.7 \%$ ), as per the screening instruments. A major proportion of the caregiver reported the symptoms of autism in the age group of 61 to 72 months (1.8-5.8\%). Children's gender, age, and socioeconomic status were not found to have any association with autistic symptoms in this setting (- Table 2). The concordance between the screening instruments was established with Cohen's kappa analysis (-Table 3). There was a slight agreement between the screening instruments on determining the caregiver reported autistic symptoms in this setting $(\mathrm{k}=0.172, p<0.010)$. The convergent validity of the screening instruments revealed a low correlation between CASI and SCDC $\left(r_{s}=0.389, p<0.001\right)$. However, a moderate agreement and strong positive correlation was found between CASI and CASI Bref items $\left(k=0.483, r_{s}=0\right.$. $69, p<0.001)$. The response rate of the shorter four-item version (CASI Bref) of CASI was calculated, and it was found that these items were significant for detecting the screen-positive cases. The association was statistically significant and found to be the predictors of autistic symptoms in this population $(\mathrm{p} \leq 0.0001)$. The variables included in the logistic regression analyses are shown in $\boldsymbol{- T a b l e} \mathbf{4}$.

\section{Discussion}

The study provides supporting evidence on caregivers reported autistic symptoms conducted in selected schools of Rohtak, Haryana. The autistic symptoms were varied from 2.2 to $18.7 \%$, depending upon the CASI (cutoff score of 10 ) and SCDC (cutoff score of 9) measurements in the present study. The variation in the prevalence in the present study should

Table 1 Profile of the study participants

\begin{tabular}{|c|c|}
\hline Variables & $N(\%)$ \\
\hline \multicolumn{2}{|l|}{ Age (in months) } \\
\hline $36-48$ & $45(20 \%)$ \\
\hline $49-60$ & $86(32.2 \%)$ \\
\hline $61-72$ & $94(41.8 \%)$ \\
\hline \multicolumn{2}{|l|}{ Sex of children } \\
\hline Boys & $130(57.8 \%)$ \\
\hline Girls & $95(42.2 \%)$ \\
\hline \multicolumn{2}{|l|}{ Socioeconomic status } \\
\hline Upper (I) & $13(5.8 \%)$ \\
\hline Upper middle (II) & $39(17.3 \%)$ \\
\hline Lower middle (III) & $95(42.3 \%)$ \\
\hline Upper lower (IV) & $57(25.3 \%)$ \\
\hline Lower $(\mathrm{V})$ & $21(9.3 \%)$ \\
\hline
\end{tabular}

aModified Kuppuswamy scale. 
Table 2 Comparison of children with and without autistic symptoms as per CASI and SCDC scale

\begin{tabular}{|c|c|c|c|c|}
\hline \multirow[t]{2}{*}{ Variables } & \multicolumn{4}{|c|}{ Caregiver report of autistic symptoms $(N=225)$} \\
\hline & $\begin{array}{l}\text { CASI } \\
\text { (score > 10) } \\
N(\%)\end{array}$ & $\begin{array}{l}p \text {-Value } \\
\left(X^{2} / \mathrm{df}\right)\end{array}$ & $\begin{array}{l}\text { SCDC } \\
(\text { score > 9) (\%) }\end{array}$ & $\begin{array}{l}p \text {-Value ( } \\
\left.X^{2} / \mathrm{df}\right)\end{array}$ \\
\hline \multicolumn{5}{|l|}{ Age (in months) } \\
\hline $36-48$ & $04(1.8 \%)$ & \multirow{3}{*}{$\begin{array}{l}0.003 \\
(11.7 / 2)\end{array}$} & $13(5.8 \%)$ & \multirow{3}{*}{$\begin{array}{l}0.288 \\
(2.48 / 2)\end{array}$} \\
\hline $49-60$ & 00 & & $19(8.4 \%)$ & \\
\hline $61-72$ & $01(0.4 \%)$ & & $10(4.4 \%)$ & \\
\hline \multicolumn{5}{|l|}{ Sex of children } \\
\hline Boys & $04(1.8 \%)$ & \multirow{2}{*}{$\begin{array}{l}0.309 \\
(1.03 / 1)\end{array}$} & $23(10.2 \%)$ & \multirow{2}{*}{$\begin{array}{l}0.661 \\
(0.19 / 1)\end{array}$} \\
\hline Girls & $01(0.4 \%)$ & & $19(8.4 \%)$ & \\
\hline \multicolumn{5}{|c|}{ Socioeconomic status } \\
\hline Upper (I) & 00 & \multirow{3}{*}{$\begin{array}{l}0.731 \\
(0.62 / 2)\end{array}$} & $9(4 \%)$ & \multirow{3}{*}{$\begin{array}{l}0.062 \\
(5.57 / 2)\end{array}$} \\
\hline Middle (II \& III) & $04(0.4 \%)$ & & $33(14.7 \%)$ & \\
\hline Lower (IV \& V) & $01(1.8 \%)$ & & $0(0 \%)$ & \\
\hline
\end{tabular}

Abbreviations: CASI, Chandigarh autism screening instrument; SCDC, social and communication disorders checklist.

Table 3 The concordance between the screening instruments

\begin{tabular}{|l|l|l|l|l|}
\hline \multicolumn{2}{|l|}{ Variable } & Kappa value & $p$-Value & Correlation \\
\hline $\begin{array}{l}\text { CASI } \\
\text { (scores of } 10 \& \text { above) }\end{array}$ & $\begin{array}{l}\text { SCDC } \\
\text { (scores of 9 \& above) }\end{array}$ & 0.172 & 0.010 & $0.364^{\mathrm{a}}$ \\
\hline $\begin{array}{l}\text { CASI } \\
\text { (scores of } 10 \& \text { above) }\end{array}$ & $\begin{array}{l}\text { CASI Bref } \\
\text { (scores of 2 \& above) }\end{array}$ & 0.483 & 0.000 & $0.626^{\mathrm{a}}$ \\
\hline
\end{tabular}

Abbreviations: CASI, Chandigarh autism screening instrument; SCDC, social and communication disorders checklist. ${ }^{\text {a }} p<0.001$.

Table 4 Predictors autistic symptoms as per CASI Bref items

\begin{tabular}{|l|l|l|l|l|}
\hline CASI Bref items & $\begin{array}{l}\text { CASI } \\
(\text { score }>10) \\
N(\%)\end{array}$ & $\begin{array}{l}p \text {-Value } \\
\left(X^{2} / \mathrm{df}\right)\end{array}$ & $\begin{array}{l}\text { Odds ratio } \\
(95 \% \mathrm{CI})\end{array}$ & $p$-Value \\
\hline Eye contact & $13(5.8 \%)$ & $<0.0001(20.3 / 1)$ & $2.784(0.994-8.215)$ & 0.064 \\
\hline $\begin{array}{l}\text { Ability to communicate needs through } \\
\text { verbal or nonverbal means }\end{array}$ & $24(10.7 \%)$ & $<0.0001(47.1 / 1)$ & $5.438(2.131-13.878)$ & 0.000 \\
\hline Peer interaction & $12(5.3 \%)$ & $<0.0001(36.3 / 1)$ & $9.760(2.567-37.409)$ & 0.001 \\
\hline Odd, repetitive behavior & $20(8.9 \%)$ & $<0.0001(45.8 / 1)$ & $5.034(1.898-13.355)$ & 0.001 \\
\hline
\end{tabular}

Abbreviations: CASI, Chandigarh autism screening instrument; $\mathrm{Cl}$, confidence interval.

be interpreted while considering the age group and screening tools of the previous similar studies conducted in the Indian setting. A study by Rudra et al reported $20.96 \%$ of parentreported autistic symptoms as per SCDC among children aged 3 to 8 years. ${ }^{11}$ The authors of CASI conducted a large community-based study in Chandigarh, India, among children between the age group of 1 to 10 years and reported that 3.7 per 1000 children scored above cutoff on CASI. ${ }^{12}$ Although autistic symptoms were more reported in boys, we did not find any statistically significant association with sociodemographic variables. A recent study also did not identify any significant predictors of caregiver-reported autistic traits with sociodemographic variables. ${ }^{13}$

We compared the autistic symptoms as per the Hindi versions of CASI and SCDC and found a slight concordance and low correlation on the intended outcome measures. These findings can be considered, based on the fact that SCDC is a screening instrument for detecting early the social and communicative deficits in autism. ${ }^{14}$ In our study, a moderate agreement and strong positive correlation were found between CASI and CASI Bref. Furthermore, all the items of CASI Bref were identified as predictors detecting autistic symptoms in this population. Moreover, CASI Bref was shown to possess good convergent validity as compared with SCDC for the early identification of autistic traits. One of the previous studies reported that SCDC is superior in detecting unspecific autistic traits. ${ }^{15}$ The results of the study suggest that CASI Bref can be a unique and efficient quick screener for autistic traits in this setting.

The present study has certain limitations. The study sample was obtained by a convenient sampling method and 
included those caregivers who can read and write the Hindi language. The results of the study relied on self-reported standard diagnostic tools and no measures were undertaken to confirm the diagnosis due to logistic reasons. We used the SCDC scale to compare CASI, due to the absence of an age-matched, accessible, and standard Hindi questionnaire, as per the study setting. Despite the limitation, the study provides insights about the preliminary evidence of the use of CASI as an autism screening questionnaire in the Indian population. The index study is the pioneering one, in that it evaluated the caregiver reported autistic symptoms with the aid of CASI among preschool children of India.

\section{Conclusion}

The study provides preliminary evidence in relation to the CASI-linked screening for autistic symptoms among preschool children. The shorter version of CASI (CASI Bref) can be an efficient quick screener for autistic traits, but the full version of CASI needs to be validated as per age-appropriate autism screening tools.

\section{Ethical Approval}

Ethical approval for the study was obtained from the Institutional Ethics Committee (IEC), Pt. B.D.S. U.H.S.RTK.

\section{Funding}

None.

\section{Conflict of Interest}

None declared.

\section{References}

1 Joseph J. Autism aetiology: the journey of discovery from the "refrigerator mother" to the neurodevelopmental hypothesis. J Child Adolesc Psych 2018;2(2):1-2

2 American Psychiatric Association, Diagnostic and statistical manual of mental disorders (DSM-5). Washington, DC: American Psychiatric Association; 2013
3 Chauhan A, Sahu JK, Jaiswal N, et al. Prevalence of autism spectrum disorder in Indian children: A systematic review and meta-analysis. Neurol India 2019;67(1):100-104

4 Kommu JVS, K R G, Srinath S, et al. Profile of two hundred children with Autism Spectrum Disorder from a tertiary child and adolescent psychiatry centre. Asian J Psychiatr 2017;28:51-56

5 Corsello CM. Early intervention in autism. Infants Young Child 2005; 18:74-85

6 Daley TC, Sigman MD. Diagnostic conceptualization of autism among Indian psychiatrists, psychologists, and pediatricians. J Autism Dev Disord 2002;32(1):13-23

7 Rudra A, Banerjee S, Singhal N, Barua M, Mukerji S, Chakrabarti B. Translation and usability of autism screening and diagnostic tools for autism spectrum conditions in India. Autism Res 2014;7(5):598-607

8 Poovathinal SA, Anitha A, Thomas R, et al. Prevalence of autism spectrum disorders in a semiurban community in south India. Ann Epidemiol 2016;26(9):663-665.e8

9 Arun P, Chavan BS. Development of a screening instrument for autism spectrum disorder: Chandigarh autism screening instrument. Indian J Med Res 2018;147(4):369-375

10 Andrade C, Sahoo S, Solanki C, et al. Development \& validation of the Chandigarh autism screening instrument. Indian J Med Res 2019;149(1):74-75

11 Rudra A, Belmonte MK, Soni PK, Banerjee S, Mukerji S, Chakrabarti B. Prevalence of autism spectrum disorder and autistic symptoms in a school-based cohort of children in Kolkata, India. Autism Res 2017;10(10):1597-1605

12 Arun P, Chavan BS. Chandigarh autism spectrum disorder study: prevalence in India. Neurology 2018;90(15):3-11

13 Goh DA, Gan D, Kung J, et al. Child, maternal and demographic factors influencing caregiver-reported autistic trait symptomatology in toddlers. J Autism Dev Disord 2018;48(4):1325-1337

14 Skuse DH, Mandy WP, Scourfield J. Measuring autistic traits: heritability, reliability and validity of the Social and Communication Disorders Checklist. Br J Psychiatry 2005; 187(6):568-572

15 Bölte S, Westerwald E, Holtmann M, Freitag C, Poustka F. Autistic traits and autism spectrum disorders: the clinical validity of two measures presuming a continuum of socia communication skills. J Autism Dev Disord 2011;41(1):66-72 